\title{
Effects of Degradable Mg-Ca Alloys on Dendritic Cell Function
}

\author{
K. Feser, M. KietZMann AND W. BÄUMER* \\ Department of Pharmacology, Toxicology and Pharmacy \\ University of Veterinary Medicine Hannover, Germany \\ C. KRAUSe AND F. W. BACH \\ Institute of Materials Science, Leibniz University of Hannover, Germany
}

\begin{abstract}
Degradable magnesium alloys are new materials for implants used in orthopedic and trauma surgery. The aim of this study was to investigate the influence of degradable magnesium alloys on the function of dendritic cells (DC) as these cells represent the major antigen presenting cells of the body. $\mathrm{MgP}$ (pure magnesium), $\mathrm{MgCa} 0.6$ (0.6\% calcium), $\mathrm{MgCa} 0.8$ ( $0.8 \%$ calcium), MgCa 1.0 (1\% calcium), and MgCa 1.2 (1.2\% calcium) alloys were degraded in cell culture medium. In parallel, murine bone marrow-derived DC were incubated with increasing concentrations $(0.1-10 \mathrm{mmol} / \mathrm{L})$ of magnesium chloride and calcium chloride, respectively. Incubation of DC with degradation media over 6 days had no influence on cell viability and only marginal influence on DC migration. Also, the production of $\mathrm{TNF} \alpha$ and expression of CD86 was not enhanced by incubation with degraded magnesium alloys. The mixed leukocyte reaction revealed that there was also no increase of the T-cell proliferation in comparison to untreated controls. However, there was a trend toward macrophage development at the expense of DC expansion and an enhanced DC migration was induced by incubation with higher magnesium concentrations. Particularly the latter should be verified in in vivo experiments.
\end{abstract}

KEY WORDS: dendritic cells, macrophages, magnesium alloys, T-cell activation, viability.

\footnotetext{
*Author to whom correspondence should be addressed.

E-mail: wolfgang.baeumer@tiho-hannover.de

Figures 1 and 2 appear in color online: http://jba.sagepub.com
} 


\section{INTRODUCTION}

D egradable metal implants made of magnesium alloys are under development to eliminate the need for a second operation for implant removal. Although magnesium is an exceptionally lightweight metal its fracture toughness is greater than ceramic biomaterials such as hydroxyapatite [1]. Though good biocompatibility was observed [1] a possible interaction of degraded material with immunocompetent cells, particularly professional antigen presenting cells, has not been studied yet. There is a definite need to test possible new implant candidates for biocompatibility and first studies dealing with a possible skin sensitizing potential of new alloys have recently been published [2]. A study of skin sensitizing potential was conducted as despite a continuous development in implant materials, contact dermatitis after musculoskeletal surgery is still apparent in 10-15\% of all implanted metals [3].

The implants tested in the presented in vitro study have been tested in a pilot study in rabbits and some alloys showed promising first results for bone implantation [4]. These findings are confirmed by a recent report on the excellent biocompatibility of $\mathrm{Mg}-\mathrm{Ca}$ alloys within bones [5]. Magnesium-based alloys are also combined with aluminum, zinc, and rare earth elements to modify degradation behavior of implants [6]. Thus, these degradable implants need an in vitro biocompatibility test system for possible immunomodulatory action of these alloys.

Up till now, most studies concerning possible sensitizing potential of implants have been performed in vivo $[3,6]$ or focused on lymphocytes $[7,8]$ and macrophages [9]. Possible effects of some metal salts have also been tested in vitro in human monocyte-derived dendritic cells (DC). It was demonstrated that $\mathrm{NiCl}_{2}, \mathrm{MnCl}_{2}$, and $\mathrm{MoCl}_{2}$ augment the $\mathrm{TNF} \alpha$ secretion and/or CD86 expression on DC [10]. Thus, some of the frequently used metals for implant alloys have the potential to stimulate DC. This is confirmed by studies with macrophages, where particles of TiAlV or CoCr induce the secretion of several cytokines like TNF $\alpha$, IL-1 $\beta$, IL-6, and IL-8 in human macrophages. Not only particles, but also fully dissolved salts of nickel, molybdenum, and chromium induce cytokine secretion in macrophages [11] indicating that the solid state (particulate) is not a prerequisite of activating antigen presenting cells like DC and macrophages.

This study was performed to introduce a new in vitro testing battery for possible immunotoxicological effects of newly generated magnesium alloys by means of DC function and dendritic cell-T-cell interaction. Since DC are the pivotal sentinels of the immune system as they can induce immunity as well as tolerance [12,13], it was decided to focus on 
the function of these immune cells. The cells are currently evaluated as in vitro alternatives for testing (skin-)sensitizing agents [14,15].

\section{MATERIALS AND METHODS}

\section{Manufacture of Magnesium Alloys}

Five different binary magnesium-based implant materials with increasing calcium content $(0,0.6,0.8,1.0$, and $1.2 \mathrm{wt} \% \mathrm{Ca})$ were produced at the Institute of Materials Science of the Leibniz University of Hannover. The producing process contained the casting, followed by extrusion and the machining to cylindrical specimens with a diameter of $8 \mathrm{~mm}$ and a height of $2 \mathrm{~mm}$. The casting process (gravity die casting) was carried out in an inert gas atmosphere with a crucible furnace. The following extrusion with an $800 \mathrm{kN}$ labor extrusion press was used to increase the mechanical properties of the material. Due to occurring of the dynamical recrystallization, a fine grained and homogenous microstructure was generated to improve the corrosion and degradation behavior.

\section{Dendritic Cell Generation from Bone Marrow Cultures}

High-purity bone marrow-derived DC were generated according to a standard protocol established by Lutz et al. (1999) [16] with slight modifications as previously described [17]. Briefly, bone marrow was cultivated with RPMI 1640 (Biochrom, Berlin, Germany), 10\% fetal calf serum (Biochrom, Berlin, Germany), and $50 \mu \mathrm{mol} / \mathrm{L} 2$ 2-mercaptoethanol (Sigma, Deisenhofen, Germany). The medium contained $20 \mathrm{ng} / \mathrm{mL}$ granulocyte-macrophage colony-stimulating factor (GM-CSF) (Sigma, Deisenhofen, Germany). Fresh medium supplemented with GM-CSF was added on days 3,6 , and 8 . Analysis of the day- 10 cell suspension by flow cytometry demonstrated a high yield of CD11c and major histocompatibility complex (MHC) class II-positive cells (antibodies from Pharmingen, Hamburg, Germany).

\section{Incubation with Magnesium/Calcium Salts and Alloys}

Beginning with day-3 of cultivation the DC were placed in a 12 -well plate $\left(4 \times 10^{5}\right.$ cells per well $)$ and incubated with increasing concentrations $(0.1-10 \mathrm{mmol} / \mathrm{L})$ of magnesium chloride and calcium chloride. RPMI 1640 itself contains already $0.4 \mathrm{mmol} / \mathrm{L} \mathrm{Mg}^{++}$and $0.61 \mathrm{mmol} / \mathrm{L}$ $\mathrm{Ca}^{++}$. The cell viability was determined by CellTiter $\odot \mathrm{AQ}_{\text {ueous }}$ One Solution cell proliferation assay (Promega, Mannheim, Germany). 
Five different alloys were tested by degradation of the alloys in culture medium over three days. The following alloys were tested: $\mathrm{MgP}$ (pure magnesium), $\mathrm{MgCa} 0.6$ ( $0.6 \%$ calcium), $\mathrm{MgCa} 0.8$ ( $0.8 \%$ calcium), $\mathrm{MgCa}$ 1.0 ( $1 \%$ calcium), MgCa 1.2 ( $1.2 \%$ calcium). The concentration of $\mathrm{Mg}^{++}$ and $\mathrm{Ca}^{++}$in degradation media was measured by Nanocolor Härte 20 (Macherey-Nagel, Düren, Germany). The DCs were incubated with degradation medium for 6 days. The buffer capacity of the RPMI 1640 media was sufficient to maintain the $\mathrm{pH}$ at 7.4.

The cell count of adherent (macrophages) and nonadherent cells (DC) was performed with a hemocytometer. For enumeration of adherent cells, cells were detached by trypsination.

As a positive control, a part of the cells were placed in a 96-well plate $\left(5 \times 10^{4}\right.$ cells per well) at day-9 and were stimulated by the addition of $5 \mu \mathrm{L}$ lipopolysaccharide (LPS) (E. coli, O127:B8, Sigma, Deisenhofen, Germany) working solution (500 ng/mL LPS, final concentration). The supernatant was collected $24 \mathrm{~h}$ later and stored at $-20^{\circ} \mathrm{C}$ until determination of tumor necrosis factor (TNF)- $\alpha$ by enzyme-linked immunosorbent assay (ELISA, DuoSet, R\&D Systems, Wiesbaden, Germany).

For determination of apoptosis and necrosis, the DC were stained using the Annexin V-FITC apoptosis detection kit (BD Bioscience, Heidelberg, Germany). For a brief period the DCs were incubated with Annexin V-FITC and propidium iodide according to the manufacturer's instructions, and $10^{5}$ cells were analyzed by flow cytometry (Coulter Epics XL, Beckmann, Krefeld, Germany with Expo 32 ADC Analysis). As a positive control, the DCs were treated with etoposide $(20 \mu \mathrm{g} / \mathrm{mL}$, Sigma) for $24 \mathrm{~h}$. The combination of Annexin V-FITC and propidium iodide allows the differentiation of viable cells (negative for Annexin V-FITC and propidium iodide), early apopotitic cells (positive for Annexin V-FITC negative for propidium iodide), and necrotic cells (positive for Annexin V-FITC and propidium iodide)

Three independent experiments were performed with each alloy and salt concentration.

\section{Mixed Leukocyte Reaction}

T-cells were isolated from the spleen of female NMRI mice, as described earlier [18]. In short, spleen cells were incubated in an erythrocyte lysis buffer for 5 min followed by an enrichment of T-lymphocytes achieved by adhesion of non-T-cells on cell ${ }^{+}$Petri dishes. This leads to a purity of approximately $70 \%$ T-cells. T-cells were stained with $0.5 \mu \mathrm{mol} / \mathrm{L}$ carboxyfluorescein succinimidyl ester (CFSE) (molecular probes, invitrogen, Karlsruhe, Germany) according to manufacturer's protocol. The cells $\left(1 \times 10^{5}\right.$ per well $)$ 
were seeded in a U-bottom 96 -well plate. DC $\left(1 \times 10^{4}\right.$, day-10 of culture) were added and incubated for five additional days. After 5 days, proliferation of T-cells was determined by flow cytometry.

\section{Chemotaxis Assay for Bone Marrow-derived DC}

Bone marrow-derived murine DC cultivated for 10 days with or without addition of salts or degradation media were used for chemotaxis assay. The chemotaxis assay was performed in a transwell system (Greiner, Frickenhausen, Germany) with inserts pore size of $8 \mu \mathrm{m}$. $2 \times 10^{5}$ cells were loaded onto the upper membrane. Migrated cells were determined in the lower chamber 90 min after incubation by means of a hemocytometer (VWR). Lead ( $\mathrm{PbCl}_{2}$, Merck, Darmstadt, Germany) served as positive control.

\section{RESULTS}

\section{Viability of Dendritic Cells}

The viability of DC is not significantly affected by incubation with increasing concentrations $(0.1-10 \mathrm{mmol} / \mathrm{L})$ of magnesium chloride and calcium chloride as determined by CellTiter $\odot \mathrm{AQ}_{\text {ueous }}$ One Solution cell proliferation assay (data not shown). The Annexin V-FITC and propidium iodide staining indicate that only high concentrations of calcium chloride $(10 \mathrm{mmol} / \mathrm{L})$ induce apoptosis comparable to the positive control etoposide $(20 \mu \mathrm{g} / \mathrm{mL})$. There is a slight increase of apoptosis induced by the degraded alloy media (Table 1). But this is modest compared to the increase after incubation with etoposide or $\mathrm{CaCl}$ $10 \mathrm{mmol} / \mathrm{L}$. Corresponding to the results obtained with CellTiter $\odot$ $\mathrm{AQ}_{\text {ueous }}$ One Solution there was no increase of propidium iodide positive cells (necrotic cells) compared to untreated controls in either setting (not shown). Thus, only data of Annexin-staining are presented (Table 1).

\section{Shift to Macrophage Development}

Although no significant impact on cell viability was observed, the absolute cell count of DC decreased dose dependently with increasing concentrations $(0.1-10 \mathrm{mmol} / \mathrm{L})$ of magnesium chloride and calcium chloride. Apart from the DC, the second cell types generated by the used protocol were adherent macrophages [16]. Thus, the amount of adherent cells was also determined. An increased cell number of macrophages was observed after incubation with increasing concentrations of magnesium 
Table 1. Annexin V-FITC staining of dendritic cells and CFSE staining of T-cells co-incubated with dendritic cell. Percent represents gated \% positive cells. As there was no increase of propidium iodide positive cells, only Annexin V data are shown. Etoposide $(20 \mu \mathrm{g} / \mathrm{mL})$ served as positive control for Annexin $V$ staining. Dendritic cells were incubated with increasing concentration of $\mathrm{MgCl}_{2}$ and $\mathrm{CaCl}_{2}$ or with increasing degradation media, mean $\pm S D$ of three independent experiments. ${ }^{a} p<0.05,{ }^{b} p<0.01$ compared to vehicle control.

\begin{tabular}{lcc}
\hline Incubation with & Annexin V + cells $(\%)$ & CFSE + cells $(\%)$ \\
\hline Vehicle (control) & $23.8 \pm 1.7$ & $46.5 \pm 8.0$ \\
Etoposide & $53.9 \pm 3.1^{\mathrm{b}}$ & - \\
$\mathrm{MgCl} 0.1 \mathrm{mmol} / \mathrm{L}$ & $20.5 \pm 3.3$ & $51.7 \pm 10.1$ \\
$\mathrm{MgCl} 1 \mathrm{mmol} / \mathrm{L}$ & $18.4 \pm 2.3$ & $51.9 \pm 9.2$ \\
$\mathrm{MgCl} 10 \mathrm{mmol} / \mathrm{L}$ & $20.0 \pm 2.8$ & $52.3 \pm 2.3$ \\
$\mathrm{CaCl} 0.1 \mathrm{mmol} / \mathrm{L}$ & $18.1 \pm 3.2$ & $47.5 \pm 8.0$ \\
$\mathrm{CaCl} 1 \mathrm{mmol} / \mathrm{L}$ & $20.9 \pm 4.2$ & $52.0 \pm 7.0$ \\
$\mathrm{CaCl} 10 \mathrm{mmol} / \mathrm{L}$ & $68.2 \pm 3.7^{\mathrm{b}}$ & $72.9 \pm 6.8^{\mathrm{a}}$ \\
$\mathrm{MgP}$ & $31.7 \pm 2.6^{\mathrm{a}}$ & $48.9 \pm 8.3$ \\
$\mathrm{MgCa} 0.6$ & $26.7 \pm 2.1$ & $48.4 \pm 6.6$ \\
$\mathrm{MgCa} 0.8$ & $23.4 \pm 3.2$ & $47.4 \pm 5.6$ \\
$\mathrm{MgCa} 1.0$ & $25.7 \pm 4.5$ & $50.1 \pm 6.9$ \\
$\mathrm{MgCa} 1.2$ & $23.9 \pm 2.2$ & $52.6 \pm 6.5$ \\
\hline
\end{tabular}

(Figure 1(a) and (b)) and calcium (not shown) salts. A similar trend was seen with the degraded alloys. With increasing calcium concentrations, the amount of DC counted at day-10 decreased whereas the amount of macrophages increased slightly but significantly (Figure 1(c) and (d)).

\section{No Elevation of TNF by Incubation with Magnesium/Calcium Salts or Alloys}

Incubation with increasing concentrations $(0.1-10 \mathrm{mmol} / \mathrm{L})$ of magnesium chloride and calcium chloride or with degraded alloy media did not result in significantly enhanced $\mathrm{TNF} \alpha$ secretion of DC. The positive control LPS (500 ng/mL) induced a tremendous secretion of TNF $\propto 24 \mathrm{~h}$ after incubation (Table 2).

\section{Expression of CD86 on dendritic cells after Incubation with Magnesium/Calcium Salts or Alloys}

The activation marker CD86 was not elevated on DC after incubation with magnesium chloride and calcium chloride or with degraded 

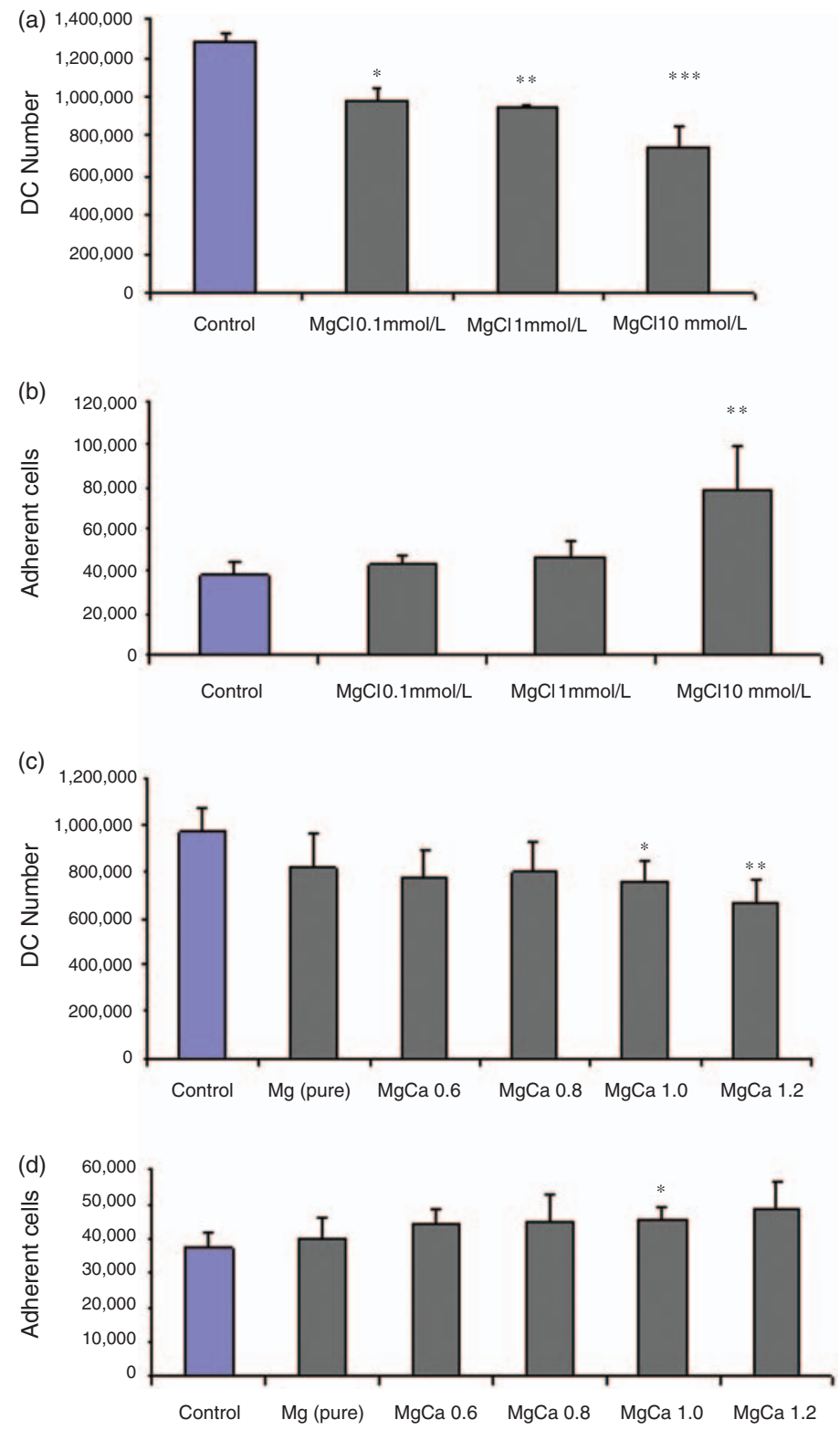

Figure 1. Dendritic cell (a) and macrophage (b) number after 6-day culture with increasing concentrations of $\mathrm{MgCl}_{2}$ or after 6-day culture in degraded media (c, d). There is a dose dependent decrease of dendritic cell numbers and an increase of macrophages with increasing concentration of $\mathrm{MgCl}_{2}$ and with increasing concentrations of calcium in the alloys. ${ }^{*} p<0.05,{ }^{* *} p<0.01,{ }^{* * *} p<0.001, n=5$. 
Table 2. CD86 expression on dendritic cell and concentration of $T N F \alpha$ in supernatants of DC incubated with magnesium chloride and calcium chloride or with degraded alloy media over six days or with LPS $(500 \mathrm{ng} / \mathrm{mL})$ for $24 \mathrm{~h}$, mean $\pm S D$ of four independent experiments. ${ }^{a} p<0.01$ compared to control.

\begin{tabular}{lcc}
\hline Incubation with & TNF $\alpha$ (pg/mL) & $\begin{array}{c}\text { CD11c/CD86 } \\
\text { positive cells }(\%)\end{array}$ \\
\hline Vehicle (control) & $44 \pm 31$ & $7.1 \pm 1.2$ \\
$\mathrm{LPS}$ & $693 \pm 195^{\mathrm{a}}$ & $24.8 \pm 11.7^{\mathrm{a}}$ \\
$\mathrm{MgCl} 0.1 \mathrm{mmol} / \mathrm{L}$ & $117 \pm 56$ & $7.4 \pm 0.8$ \\
$\mathrm{MgCl} 1 \mathrm{mmol} / \mathrm{L}$ & $109 \pm 75$ & $6.8 \pm 2.1$ \\
$\mathrm{MgCl} 10 \mathrm{mmol} / \mathrm{L}$ & $123 \pm 72$ & $7.9 \pm 3.1$ \\
$\mathrm{CaCl} 0.1 \mathrm{mmol} / \mathrm{L}$ & $99 \pm 56$ & $8.9 \pm 2.7$ \\
$\mathrm{CaCl} 1 \mathrm{mmol} / \mathrm{L}$ & $112 \pm 41$ & $7.7 \pm 3.3$ \\
$\mathrm{CaCl} 10 \mathrm{mmol} / \mathrm{L}$ & $103 \pm 20$ & $7.8 \pm 1.2$ \\
$\mathrm{MgP}$ & $62 \pm 30$ & $7.0 \pm 1.6$ \\
$\mathrm{MgCa} 0.6$ & $66 \pm 34$ & $5.3 \pm 2.2$ \\
$\mathrm{MgCa} 0.8$ & $68 \pm 37$ & $8.3 \pm 3.0$ \\
$\mathrm{MgCa} 1.0$ & $87 \pm 27$ & $10.2 \pm 3.8$ \\
$\mathrm{MgCa} 1.2$ & $80 \pm 39$ & $9.0 \pm 3.9$ \\
\hline
\end{tabular}

alloy media. Again, the positive control (LPS) induced a distinct increase in CD86/CD11c double-positive cells (Table 2).

\section{Mixed Leukocyte Reaction after Incubation with Magnesium/ Calcium Salts or Alloys}

The mixed leukocyte reaction is a parameter for T-cell activation by allogeneic DC. Again, an incubation of DC with magnesium chloride or with degraded alloy media over 5 days did not enhance the allogeneic T-cell proliferation (Table 1). Only high concentrations of $\mathrm{CaCl}_{2}$ $(10 \mathrm{mmol} / \mathrm{L})$ led to a pronounced increase of T-cell proliferation. However, this (unphysiological) high concentration also led to enhanced DC apoptosis (Table 1).

\section{Increased DC Migration with Increasing Magnesium and Calcium Concentrations}

There was an increase of DC migration, which became significant at the highest concentration $(10 \mathrm{mmol} / \mathrm{L})$. Again, the degraded alloys induced an increased DC migration in alloys with the highest calcium concentrations (Figure 2). Lead $\left(\mathrm{PbCl}_{2}\right)$ was taken as a positive control as it was described that lead induces an increased DC migration [19]. 

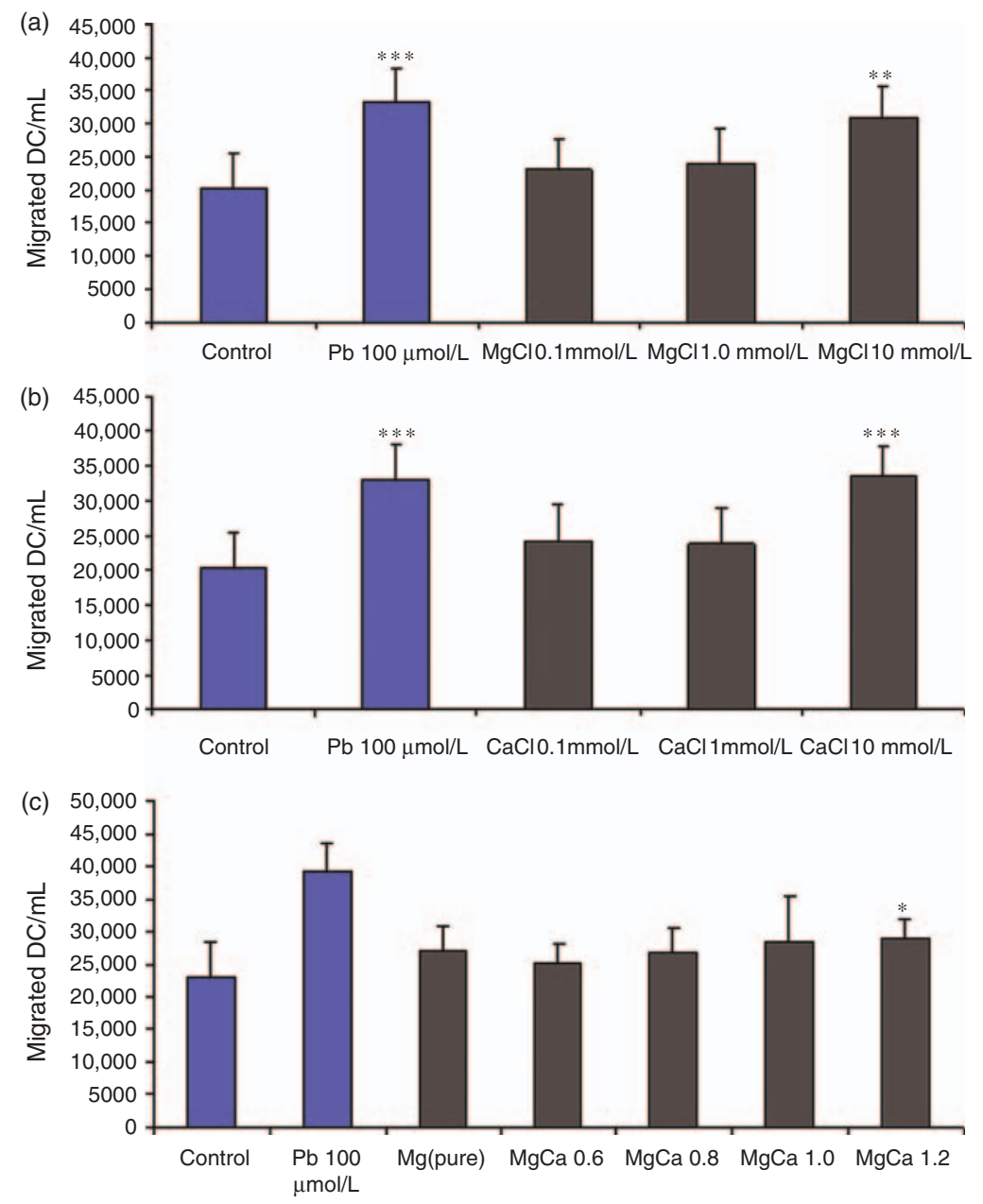

Figure 2. Dendritic cell migration measured in a transwell system. There is a significant increase in dendritic cell migration with the highest concentration of $\mathrm{MgCl}_{2}$ ((a) $\left.10 \mathrm{mmol} / \mathrm{L}\right)$, $\mathrm{CaCl}_{2}$ ((b) $\left.10 \mathrm{mmol} / \mathrm{L}, \mathrm{B}\right)$, and degradation media (c). Lead $\left(\mathrm{PbCl}_{2} 100 \mu \mathrm{mol} / \mathrm{L}\right)$ was taken as a positive control. ${ }^{*} p<0.05$, ${ }^{* *} p<0.01,{ }^{* * *} p<0.001, n=9$, pooled from three independent experiments.

\section{DISCUSSION}

Magnesium-based materials were first introduced as orthopedic biomaterials in the first half of the last century. However, the basic problem was that pure magnesium metal corroded too rapidly in vivo by producing a large amount of gas which resulted in subcutaneous bubbles [1]. 
This fast corrosion is enhanced by the physiological $\mathrm{pH}$ of 7.4 and the high chloride environment of the physiological system. It is intended to modify the degradation time by addition of calcium to the magnesium alloys and also to have a positive impact on stability criteria [4].

Most important is that the amount of liberated magnesium in the direct environment of the degrading magnesium alloy has to be estimated. Whereas $\mathrm{Mg}^{++}$deficiency is accompanied by a range of clinical symptoms $\mathrm{Mg}^{++}$toxicity seems to be extremely rare. First side-effects occur at total plasma $\mathrm{Mg}^{++}$of $3.5-5 \mathrm{mmol} / \mathrm{L}$ and severe side-effects leading to heart arrest occur only at extremely high plasma concentrations of $5-15 \mathrm{mmol} / \mathrm{L}$ [20]. Thus, a systemic effect can nearly be excluded as the level of magnesium in the extracellular fluid ranges between 0.7 and $1.05 \mathrm{mmol} / \mathrm{L}$ [20] and a quite tight homeostasis is maintained by the kidneys and intestine. A hyper-magnesiemia is rare due to the efficient excretion of the element in the urine [20]. Our results obtained by microdialysis technique indicate that concentrations of $3.7( \pm 1.0) \mathrm{mmol} / \mathrm{L}($ mean $\pm \mathrm{SD})$ can be achieved after an incubation time of five hours in the direct environment of a pure magnesium alloy (S. Schumacher, personal communication). This microdialysis study was performed in the skin of eight isolated perfused udders as described earlier [21]. These results correspond to the maximum concentration found in alloy degradation media (Table 3) with about $3-4 \mathrm{mmol} / \mathrm{L}$. When degradation media were analyzed, the increase of the calcium concentration was always $<0.2 \mathrm{mmol} / \mathrm{L}$.

There are two results that warrant further examination. First, the influence of $\mathrm{Mg}^{++}$on the DC development. There seems to be a favor for macrophage development in an environment of higher $\mathrm{Mg}^{++}$levels. Whether this has any physiological relevance has to be determined in vivo, for example, by differential staining of macrophages and $\mathrm{DC}$ at the site of implantation. Second, the enhanced DC migration. Although this phenomenon is quite moderate, it is a robust, reproducible finding. This also has to be determined in different settings, for example, DC migration assays in vivo. The enhanced apoptosis and T-cell

Table 3. Concentration of $\mathrm{Mg}(\mathrm{mmol} / \mathrm{L})$ in degraded media $(n=8$ each group), which was taken for dendritic cell incubation.

\begin{tabular}{lccccc}
\hline & MgP & MgCa 0.6 & MgCa 0.8 & MgCa 1.0 & MgCa 1.2 \\
\hline Minimum & 0.42 & 1.07 & 0.77 & 0.95 & 0.68 \\
25\% Percentile & 0.54 & 1.20 & 1.07 & 1.08 & 1.12 \\
Median & 1.00 & 1.28 & 1.29 & 1.38 & 1.47 \\
75\% Percentile & 1.57 & 1.63 & 1.59 & 2.89 & 1.95 \\
Maximum & 1.64 & 1.74 & 1.74 & 3.48 & 2.08 \\
\hline
\end{tabular}


proliferation induced by the high $\mathrm{CaCl}_{2}$ concentration $(10 \mathrm{mmol} / \mathrm{L})$ is not of (patho) physiological relevance, as these concentrations will not be achieved even with alloys containing higher calcium concentrations.

Taken together a new in vitro testing battery for possible immunotoxicological effects was established with murine bone marrow-derived DC. End points for DC function were viability (Annexin V/propidium iodide assay), DC migration (transwell system), DC activation ( $\mathrm{TNF} \alpha$ secretion and CD86 expression) and T-cell activation (mixed leukocyte reaction). Incubation of DC with degradation media over 6 days had no influence on cell viability and only marginal influence on $\mathrm{DC}$ migration. Also, the production of TNF $\alpha$ and CD86 was not significantly enhanced by incubation with degraded magnesium alloys. The mixed leukocyte reaction showed no increase of the T-cell proliferation in comparison to untreated controls. Only artificial high concentrations of calcium increased the mixed leukocyte reaction. The positive controls (LPS stimulation, incubation with etoposide, $\mathrm{PbCl}_{2}$ as chemoattractant) led to expected reactions and activation in DC. As the incubation with increasing concentrations of magnesium and calcium chloride did also fail to influence the above mentioned parameters it can be concluded that degradable magnesium alloys tested might only have influence on DC migration. However, if an enhanced migration is associated with a biological relevant activation of DC it must be verified in adequate in vivo experiments.

\title{
CONCLUSION
}

$\mathrm{Mg}-\mathrm{Ca}$ alloys are promising new degradable alloys with excellent biocompatibility. The present study demonstrate that $\mathrm{Mg}^{++}$and $\mathrm{Ca}^{++}$ from degraded alloys do not significantly interfere with DC functions in those concentrations anticipated by in vitro degradation experiments.

\section{NOMENCLATURE}

\author{
$\mathrm{Al}=$ Aluminum \\ $\mathrm{Ca}=$ Calcium \\ $\mathrm{CD}=$ Cluster of differentiation \\ CFSE $=$ Carboxyfluorescein succinimidyl ester \\ $\mathrm{Cr}=$ Cromnium \\ $\mathrm{DC}=$ Dendritic cells \\ $\mathrm{IL}=$ Interleukin \\ $\mathrm{Mg}=$ Magnesium \\ $\mathrm{Ti}=$ Titanium \\ $\mathrm{TNF} \alpha=$ Tumor necrosis factor $\alpha$
}




\section{ACKNOWLEDGMENT}

This study is supported by the Deutsche Forschungsgemeinschaft (SFB599, R1). Wolfgang Bäumer is appointed as an endowed professor in 'Veterinary Dermatopharmacology' granted by Bayer Animal Health $\mathrm{GmbH}$.

\section{REFERENCES}

1. Staiger, M.P., Pietak, A.M., Huadmai, J. and Dias, G. Magnesium and Its Alloys as Orthopedic Biomaterials: A Review, Biomaterials, 2006: 27: $1728-1734$.

2. Witte, F., Abeln, I., Switzer, E., Kaese, V., Meyer-Lindenberg, A. and Windhagen, H. Evaluation of the Skin Sensitizing Potential of Biodegradable Magnesium Alloys, J. Biomed. Mater. Res. A, 2008: 86: 1041-1047.

3. Hallab, N., Merritt, K. and Jacobs, J.J. Metal Sensitivity in Patients with Orthopaedic Implants, J. Bone Joint Surg. Am., 2001: 83-A: 428-436.

4. von der Hoh, N., Krause, A., Hackenbroich, C., Bormann, D., Lucas, A. and Meyer-Lindenberg, A. Influence of Different Surface Machining Treatments of Resorbable Implants made from Different Magnesium-Calcium Alloys on their Degradation-A Pilot Study in Rabbit Models, Dtsch. Tierarztl. Wochenschr., 2006: 113: 439-446.

5. Li, Z., Gu, X., Lou, S. and Zheng, Y. The Development of Binary Mg-Ca Alloys for Use as Biodegradable Materials within Bone, Biomaterials, 2008: 29: $1329-1344$.

6. Witte, F., Kaese, V., Haferkamp, H. et al. In Vivo Corrosion of Four Magnesium Alloys and the Associated Bone Response, Biomaterials, 2005: 26: $3557-3563$.

7. Hallab, N.J., Anderson, S., Stafford, T., Glant, T. and Jacobs, J.J. Lymphocyte Responses in Patients with Total Hip Arthroplasty, J. Orthop. Res., 2005: 23: 384-391.

8. Hallab, N.J., Caicedo, M., Epstein, R., McAllister, K. and Jacobs, J.J. In Vitro Reactivity to Implant Metals Demonstrates a Person-dependent Association with Both T-Cell and B-Cell Activation, J. Biomed. Mater. Res. A, 2009: 92A: 667-682.

9. Kaufman, A.M., Alabre, C.I., Rubash, H.E. and Shanbhag, A.S. Human Macrophage Response to UHMWPE, Tialv, Cocr, and Alumina Particles: Analysis of Multiple Cytokines Using Protein Arrays, J. Biomed. Mater. Res. A, 2008: 84: 464-474.

10. Manome, H., Aiba, S. and Tagami, H. Simple Chemicals Can Induce Maturation and Apoptosis of Dendritic Cells, Immunology, 1999: 98: 481-490.

11. Caicedo, M.S., Desai, R., McAllister, K., Reddy, A., Jacobs, J.J. and Hallab, N.J. Soluble and Particulate Co-Cr-Mo Alloy Implant Metals Activate the Inflammasome Danger Signaling Pathway in Human Macrophages: A Novel Mechanism for Implant Debris Reactivity, J. Orthop. Res., 2009: 27: $847-854$. 
12. Banchereau, J. and Steinman, R.M. Dendritic Cells and the Control of Immunity, Nature, 1998: 392: 245-252.

13. Novak, N. and Bieber, T. Dendritic Cells as Regulators of Immunity and Tolerance, J. Allergy Clin. Immunol., 2008: 121: S370-S374.

14. Kimber, I., Cumberbatch, M., Betts, C.J. and Dearman, R.J. Dendritic Cells and Skin Sensitisation Hazard Assessment, Toxicol. In Vitro, 2004: 18: 195-202.

15. Ryan, C.A., Gerberick, G.F., Gildea, L.A. et al. Interactions of Contact Allergens with Dendritic Cells: Opportunities and Challenges for the Development of Novel Approaches to Hazard Assessment, Toxicol. Sci., 2005: 88: 4-11.

16. Lutz, M.B., Kukutsch, N., Ogilvie, A.L. et al. An Advanced Culture Method for Generating Large Quantities of Highly Pure Dendritic Cells from Mouse Bone Marrow, J. Immunol. Methods, 1999: 223: 77-92.

17. Baumer, W., Krekeler, S., DeVries, V.C., Niedorf, F., Tschernig, T. and Kietzmann, M. Non-steroidal and Steroidal Anti-Inflammatory Drugs Vary in their Modulation of Dendritic Cell Function in the Elicitation Phase of Allergic Contact Dermatitis, Exp. Dermatol., 2006: 15: 322-329.

18. Baumer, W., Sulzle, B., Weigt, H. et al. Cilomilast, Tacrolimus and Rapamycin Modulate Dendritic Cell Function in the Elicitation Phase of Allergic Contact Dermatitis, Br. J. Dermatol., 2005: 153: 136-144.

19. Hunermann, C. (2006). Studies on Heavy Metals and their Influence on Dendritic Cell Function, PhD Thesis, University of Veterinary Medicine, Hannover, Germany.

20. Saris, N.E., Mervaala, E., Karppanen, H., Khawaja, J.A. and Lewenstam, A. Magnesium: An Update on Physiological, Clinical and Analytical Aspects, Clin. Chim. Acta, 2000: 294: 1-26.

21. Baumer, W. and Kietzmann, M. The Isolated Perfused Bovine Udder as a Model of Dermal Eicosanoid Release, Altern. Lab. Anim., 2000: 28: 643-649. 